\title{
Erratum to: Exposure to mild temperatures decreases overwintering larval survival and post-diapause reproductive potential in the rice stem borer Chilo suppressalis
}

\author{
Haijun Xiao $^{1,2} \cdot$ Junhui Chen $^{1} \cdot$ Liyuan Chen $^{1} \cdot$ Chao Chen $^{1} \cdot$ Shaohui $\mathrm{Wu}^{3}$
}

Published online: 4 August 2016

(C) Springer-Verlag Berlin Heidelberg 2016

\section{Erratum to: J Pest Sci}

\section{DOI 10.1007/s10340-016-0769-0}

Unfortunately, there is an error in Fig. 4 in the original publication of the article. The correct version of Fig. 4 is given below:
The online version of the original article can be found under doi:10.1007/s10340-016-0769-0.

\section{Haijun Xiao}

haijunxiao@hotmail.com; hjxiao@jxau.edu.cn

1 Institute of Entomology, Jiangxi Agricultural University, Nanchang 330045, China

2 State Key Laboratory for Biology of Plant Diseases and Insect Pests, Institute of Plant Protection, Chinese Academy of Agricultural Sciences, Beijing 100193, China

3 Department of Entomology, Rutgers, the State University of New Jersey, New Brunswick, NJ 08901-8554, USA
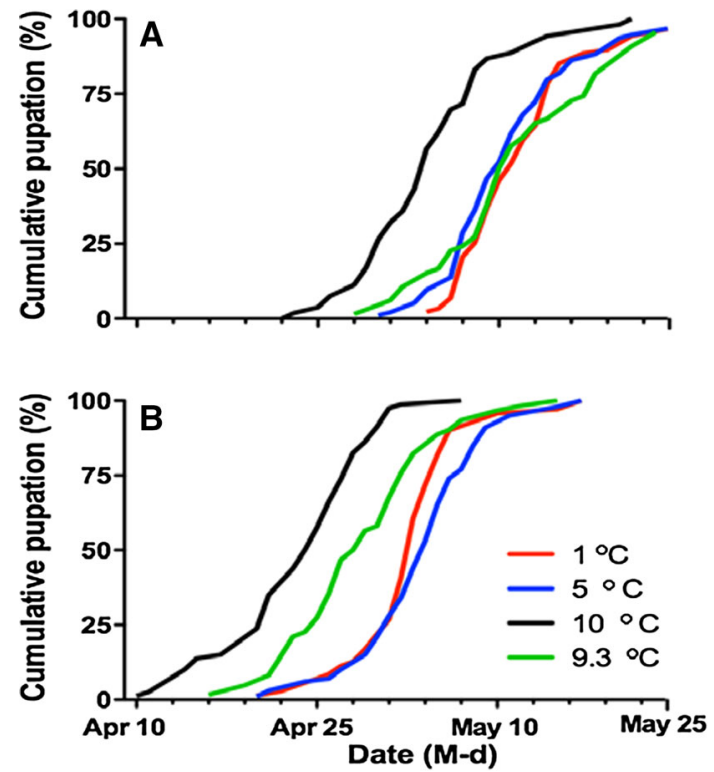

Fig. 4 Cumulative pupation rates of overwintering larvae of $C$. suppressalis. Diapausing larvae of both the third (a) and fourth (b) generations were kept at 1,5 and $10{ }^{\circ} \mathrm{C}$ and a daily mean temperature of $9.3{ }^{\circ} \mathrm{C}$ until the termination of diapause on 31 March and then were transferred to natural conditions 